\title{
Mode II fracture energy in the adhesive bonding of dissimilar substrates: carbon fibre composite to aluminium joints
}

\author{
Cristina Alía, José M. Arenas' , Juan C. Suárez, Rosa Ocaña and Julián J. Narbón
}

\begin{abstract}
The end-notched flexure (ENF) test calculates the value of mode II fracture energy in adhesive bonding between the substrates of same nature. Traditional methods of calculating fracture energy in the ENF test are not suitable in cases where the thickness of the adhesive is non-negligible compared with adherent thicknesses. To address this issue, a specific methodology for calculating mode II fracture energy has been proposed in this paper. To illustrate the applicability of the proposed method, the fracture energy was calculated by the ENF test for adhesive bonds between aluminium and a composite material, which considered two different types of adhesive (epoxy and polyurethane) and various surface treatments. The proposed calculation model provides higher values of fracture energy than those obtained from the simplified models that consider the adhesive thickness to be zero, supporting the conclusion that the calculation of mode II fracture energy for adhesives with non-negligible thickness relative to their adherents should be based on mathematical models, such as the method proposed in this paper, that incorporate the influence of this thickness.
\end{abstract}

\section{Introduction}

Currently, many industrial sectors (automotive, aeronautical, naval and others) are researching and experimenting with new materials. These new materials must provide structures that are increasingly light and strong to achieve the broader goal of attaining greater speeds with less energy consumption. Given these considerations, polymeric matrix composites that are reinforced with carbon fibre are of great industrial interest.[1-4]

However, in actual products, there are other components and parts that are made of steel or aluminium alloys that must be joined to the composite material. In such joints, the use of structural adhesives rather than traditional systems (such as welding or riveting, for instance) provides the end product with a lighter weight, more uniform tension distribution and improved tightness; eliminates galvanic corrosion; and generates a myriad of other benefits.[5] Studies have been conducted that either evaluate the mechanical behaviour of the adhesive bonds that join aluminium with a composite [6-8] or provide an experimental procedure that measures the adhesive bond strength of a joint between a composite and steel.[9-12] 
Jumel et al. [13] analysed the propagation of the crack and the process zone with end-notched flexure (ENF) specimens for adhesive bonding of aluminium/epoxy. This test is presented for exploitation with a new experimental methodology using the backface strain monitoring technique. Stresses and strains in both adherents and the adhesive layer have been evaluated. Also, compliance and energy release rate have been obtained. This model is compared to a simplified case, from which a comprehensive experimental method is proposed for precise monitoring of crack propagation and measurement of interface shear compliance during the ENF experiment.

Budzik et al. [14] studied data reduction. Also, they made an experimental study of crack propagation and process zone with ENF specimens for adhesive bonding of aluminium/epoxy. The new results permitted validation of simple or refined analytical/numerical models including those of the cohesive zone. In addition, the backface strain gauge monitoring technique exhibited unexpected mode I contributions, quantitatively evaluated.

To maximise the inherent benefits of adhesives, the application of adhesive bonds requires a specific design of the adhesive joint that enhances its performance and reduces its limitations (these design aspects may include careful surface preparation, the reduction of the joint's resistance to peeling, and other components).[15-17] As a result, numerous studies have been performed to either establish analytical models of structural adhesive joints that could allow for the better understanding of adhesive behaviour [18,19] or to propose criteria to optimise the design of joints.[20-23] If the joint geometry is complex, analytical models can be replaced by finite element models for the study of the adhesive joint's behaviour.[24-27]

Typically, the selection of critical design parameters (such as the type of adhesive used, surface treatments, adhesive thickness, joint geometry and other design facets) is based only on tensile shear strength tests. However, for critical industrial applications in which the safety and health of persons or property are at risk, one needs a guarantee of adequate reliability. Shear tests cannot provide the requisite assurances because they do not adequately evaluate the behaviour of the bond when features such as detached areas, pores, cracks or other irregularities appear in the adhesive joint.

It is therefore necessary to complement previous studies with an experimental evaluation of the adhesive bond's shear resistance that incorporates the characteristic criteria of fracture mechanics. This combined study will provide a better understanding of an adhesive bond and a better assessment of its performance.

One of the methods most often used for the experimental evaluation of shear behaviour is the ENF test, which calculates the value of the fracture energy required for the onset of interlaminar crack propagation by shear strength.

The ENF test was initially proposed by Carlsson [28] and consists of a three-point bending test in which the pre-existing interlaminar crack is forced to propagate by shear stresses that appear on both surfaces of the crack. These shears are generated when the sample is flexurally loaded at three points and a relative movement between both surfaces of the crack occurs, causing its mode II propagation. This test is most often used to evaluate mode II propagation due to its relatively simple configuration. However, the test does produce a degree of instability in the propagation of the crack, and thus it only allows for the precise determination of the initial values of the fracture energy when $a_{0}<0.7 \mathrm{~L}$. [28] This problem is solved by conducting real-time, continuous monitoring of the load that measures the displacement of the crack. Analyses of ENF tests using numerical methods allow for a reduction in data that makes it feasible to experimentally determine the mode II adhesive fracture energy. [29-31] Several authors [32] have already applied this methodology to the study of adhesive bonds in composite materials. 
To calculate the fracture energy in the ENF test, two procedures are typically used, i.e. the experimental calibration of the flexibility method (EC) and the corrected beam theory (CBT). However, these methods do not allow for the calculation of the fracture energy of structural adhesive bonds with adherents of different thicknesses. Therefore, this paper proposes a specific methodology for calculating the mode II fracture energy. This methodology, which uses a modification of the Bernoulli-Euler beam theory, can be applied to adhesive bonds with adherents of different thicknesses.

To illustrate the applicability of the proposed method, the calculation of the fracture energy by the ENF test in adhesive bonds between aluminium and a composite has been performed in this study. The results obtained have permitted the identification of the adhesive and surface treatments that are most suitable for this type of joint.

The main object of this work is to find a suitable but simple test to compare the influence of different surface preparation procedures on the performance of adhesion joints. ENF test is a very convenient test, provided that the basic equations are modified to include the influence of thick adhesive layers and the effect of dissimilar adherends, as expected in actual applications. In this way, it is possible to obtain an apparent value of $G_{\mathrm{IIC}}$ (ignoring any possible contribution of mode I loading) that is good enough for comparison among different surface preparations, but not appropriate to derive allowable design values of $G_{\text {IIC }}$.

\section{Methods for calculating the fracture energy}

Figure 1 illustrates the characteristic parameters of an aluminium-composite adhesive bond that has been prepared for conducting the ENF test. In the ENF test, the calculation of the fracture energy is more straightforward if the neutral line position of the adhesive bond is in the centre of the union. To achieve this purpose, given that the Poisson's ratios for aluminium and composite have similar values ( 0.26 and 0.28 , respectively), the following decoupling condition applies for the flexure test [33]:

$$
\frac{h_{2}}{h_{1}}=\left(\frac{E_{1}}{E_{2}}\right)^{1 / 3}
$$

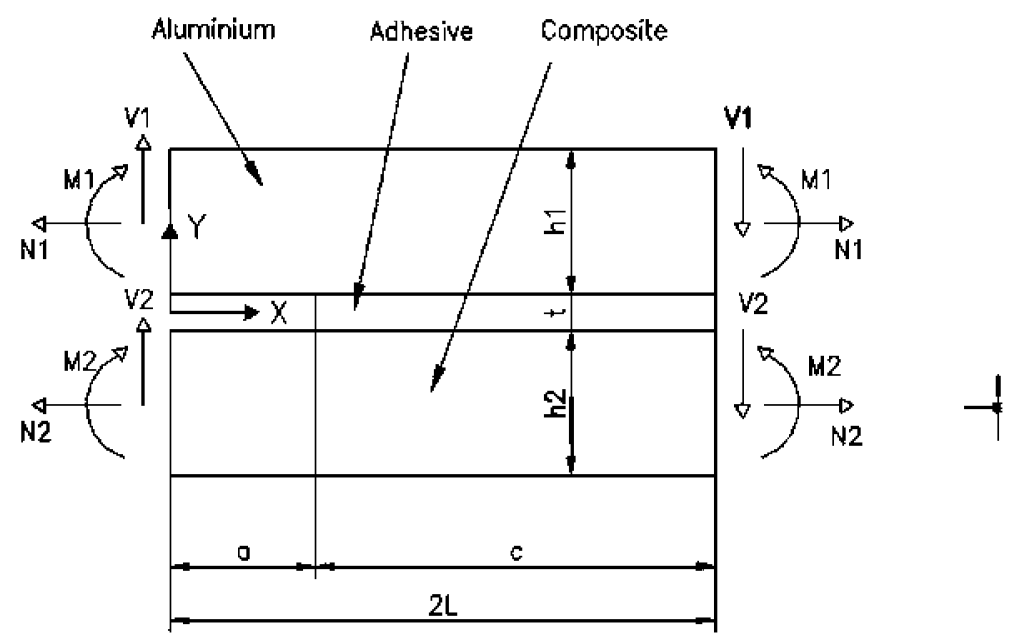

Figure 1. The geometry of the samples for the ENF test of aluminium-composite joints. 
where $h_{1}$ is the thickness of the aluminium, $h_{2}$ is the thickness of the composite, $E_{1}$ is Young's modulus for aluminium and $E_{2}$ is Young's modulus for the composite.

As the adherent thickness of the aluminium sample $(2 \mathrm{~mm})$ and the flexural modulus for both aluminium and the composite $\left(6.6 \cdot 10^{10} \mathrm{~Pa}\right.$ and $1.69 \cdot 10^{10} \mathrm{~Pa}$, respectively) were known, Equation (1) was applied to calculate the thickness of the suitable composite $(2.3 \mathrm{~mm})$. This thickness value causes the product of Young's modulus and the moment of inertia to be constant in both adherents and confirms that the neutral line position is situated in the adhesive layer, as it does not coincide with the midline of the specimen. Using these specific different thicknesses for each adherent allows us to equalise their flexure stiffness, and therefore situates the neutral line in the centre of the adhesive layer.

Ouyang and $\mathrm{Li}[33]$ proposed the following equation to calculate the fracture energy from the ENF test:

$$
G_{\mathrm{IIC}}=\frac{\frac{1}{2}\left[\frac{h_{1} a Q_{T}}{2 D_{1}}\right]^{2}+\frac{\left(h_{1}+h_{2}\right) Q_{T} \delta_{o}}{2\left(D_{1}+D_{2}\right)}}{\frac{1}{A_{1}}+\frac{1}{A_{2}}+\frac{\left(h_{1}+h_{2}\right)^{2}}{4\left(D_{1}+D_{2}\right)}}
$$

where

$G_{I I C}=$ the mode II fracture energy.

$v_{1}$ and $v_{2}=$ Poisson's ratios for the two adherents.

$a=$ the length from the adherent end to the start of the crack.

$Q_{T}=$ half of the adhesive rupture strength.

$\delta_{0}=$ the shear displacement of the crack tip.

$A_{1}=\frac{E_{1} h_{1}}{1-v_{1}^{2}}$; where $E_{1}, h_{1}$ and $v_{1}$ are Young's modulus, thickness and Poisson's ratio of aluminium, respectively.

$A_{2}=\frac{E_{2} h_{2}}{1-v_{2}^{2}}$, where $E_{2}, h_{2}$ and $v_{2}$ are Young's modulus, thickness and Poisson's ratio of the composite, respectively.

$D_{1}=\frac{E_{1} h_{1}^{3}}{12\left(1-v_{1}^{2}\right)}$, where $E_{1}, h_{1}$ and $v_{1}$ are Young's modulus, thickness and Poisson's ratio of aluminium, respectively.

$D_{2}=\frac{E_{2} h_{2}^{3}}{12\left(1-v_{2}^{2}\right)}$, where $E_{2}, h_{2}$ and $v_{2}$ are Young's modulus, thickness and Poisson's ratio of the composite, respectively.

Equation (2) is valid if the thickness of the adhesive is much lesser than the thickness of the adherents. However, in many industrial applications, an adhesive is used with a thickness that is not negligible compared with the thicknesses of the adherents. Therefore, this paper will propose a modification of the Bernoulli-Euler beam theory to calculate the fracture energy of adhesive joints in a manner that accounts for both the thickness of the adhesive and the different thicknesses of the adherents.

Branco [34] proposed that the shear stress variations along the thickness of each of the bonded adherents are given by:

$$
\tau=\frac{3 P}{2 A}\left(1-\frac{y^{2}}{c^{2}}\right)
$$

where 
$\tau$ : shear stress.

$y$ : the distance from the surface to the considered position in the adherent.

$P$ : the rupture strength of the adhesive.

$A$ : the cross-sectional area of the adherends.

$c$ : the half height.

Figure 1 illustrates the generalised loadings that occurs in the bond where $\mathrm{N}_{1,2}$ are normal forces, $\mathrm{V}_{1,2}$ are transversal forces and $\mathrm{M}_{1,2}$ are bending moments for each adherents, aluminium and composite, respectively.

In the case of the adhesive joint configuration in Figure 1 (two different adherents with different thicknesses), the parameters of Equation (3) acquire the values shown in Table 1.

The strain energy $(U)$ will be the sum of the flexural strain energy $\left(U_{f}\right)$ and the shear strain energy $\left(U_{c}\right)$ :

$$
U=U_{f}+U_{c}
$$

In the case of the adhesive joint in the configuration (two adherents of different thicknesses and an adhesive of non-negligible thickness), the flexural strain energy is calculated as follows:

$$
\begin{aligned}
U_{f}= & \int_{0}^{2 L} \frac{M f^{2}}{2 E I} d x \\
= & \int_{0}^{a} \frac{\left(\frac{P x}{4}\right)^{2}}{\frac{E_{1} I_{1}}{4}} d x+\int_{0}^{a} \frac{\left(\frac{P x}{4}\right)^{2}}{\frac{E_{2} I_{2}}{4}} d x+\int_{a}^{L} \frac{\left(\frac{P x}{2}\right)^{2}}{2 E_{1} I_{1}+2 E_{2} I_{2}+2 E_{3} I_{3}} d x \\
& +\int_{L}^{2 L} \frac{\left(\frac{P x}{2}-P(x-L)\right)^{2}}{2 E_{1} I_{1}+2 E_{2} I_{21}+2 E_{3} I_{3}} d x \\
= & \frac{P^{2} a^{3}}{6 E_{1} I_{1}}+\frac{P^{2}(L-a)^{3}}{24\left(E_{1} I_{1}+E_{2} I_{2}+E_{3} I_{3}\right)}+\frac{7 P^{2} L^{3}}{24\left(E_{1} I_{1}+E_{2} I_{2}+E_{3} I_{3}\right)}
\end{aligned}
$$

where $I_{1}, I_{2}$ and $I_{3}$ are the second moments of area of aluminium, composite and adhesive, respectively. $E_{3}$ is Young's modulus of adhesive. follows:

Similarly, the shear strain energy for the configuration of Figure 1 is calculated as

Table 1. The value of the parameters of Equation (3) for the configuration of Figure 1.

\begin{tabular}{lccc}
\hline & & Aluminium & Composite \\
\hline $0<x<a$ & A & $b h_{1}$ & $b h_{2}$ \\
& $c$ & $h_{1}^{\frac{h_{1}}{2}}$ & $-\frac{3}{2}$ \\
& $\tau$ & $\frac{3 P}{2 b h_{1}}\left(1-\frac{y^{2}}{\left(\frac{h_{1}}{2}\right)^{2}}\right)$ & $\frac{3 P}{2 b h_{2}}\left(1-\frac{y^{2}}{\left(\frac{h_{2}}{2}\right)^{2}}\right)$ \\
$a<x<2 \mathrm{~L}$ & & $b h_{1}$ & $b h_{2}$ \\
& $\mathrm{~A}$ & $h_{1}$ & $-h_{2}$ \\
& $c$ & $\frac{3 P}{2 b h_{1}}\left(1-\frac{y^{2}}{\left(h_{1}\right)^{2}}\right)$ & $\frac{3 P}{2 b h_{2}}\left(1-\frac{y^{2}}{\left(-h_{2}\right)^{2}}\right)$ \\
\hline
\end{tabular}




$$
\begin{aligned}
U_{c}= & \int_{0}^{2 l} \int_{-h}^{h} \frac{\tau^{2}}{2 G} b d y d x=\int_{0}^{a} \int_{0}^{\frac{h_{1}}{2}} \frac{\tau\left(c=\frac{h_{1}}{2}\right)^{2}}{2 G_{1}} b d y d x \\
& +\int_{0}^{a} \int_{0}^{\frac{h_{2}}{2}} \frac{\tau\left(c=\frac{h_{2}}{2}\right)^{2}}{2 G_{2}} b d y d x+\int_{a}^{2 L} \int_{0}^{h_{1}} \frac{\tau\left(c=h_{1}\right)^{2}}{2 G_{1}} b d y d x \\
& +\int_{a}^{2 L} \int_{0}^{h_{2}} \frac{\tau\left(c=h_{2}\right)^{2}}{2 G_{2}} b d y d x+\int_{a}^{2 L} \int_{0}^{t} \frac{\tau(c=t)^{2}}{2 G_{3}} b d y d x=\frac{9 P^{2} a}{30 b}\left[\frac{1}{h_{1} G_{1}}+\frac{1}{h_{2} G_{2}}\right] \\
& +\frac{9 P^{2}(2 L-a)}{15 b}\left[\frac{1}{h_{1} G_{1}}+\frac{1}{h_{2} G_{2}}+\frac{1}{t G_{3}}\right]
\end{aligned}
$$

where $G_{1}, G_{2}$ and $G_{3}$ are the aluminium, composite and adhesive shear moduli, respectively.

Castigliano's Theorem establishes that the strain energy derivative for one of the loads applied to the solid is equal to the projection of the displacement of the application point of the load along its direction. Accordingly, the displacement $\delta$ of the load application point can be determined using the following expression [35]:

$$
\delta=d U / d P
$$

Expanding this expression, we obtain the following equation:

$$
\begin{aligned}
\delta= & \frac{d U}{d P}=\frac{P a^{3}}{6 E_{1} I_{1}}+\frac{P(L-a)^{3}}{24\left(E_{1} I_{1}+E_{2} I_{2}+E_{3} I_{3}\right)}+\frac{7 P L^{3}}{24\left(E_{1} I_{1}+E_{2} I_{2}+E_{3} I_{3}\right)} \\
& +\frac{9 p a}{30 b}\left[\frac{1}{h_{1} G_{1}}+\frac{1}{h_{2} G_{2}}\right]+\frac{9 p(2 L-a)}{15 b}\left[\frac{1}{h_{1} G_{1}}+\frac{1}{h_{2} G_{2}}+\frac{1}{t G_{3}}\right]
\end{aligned}
$$

The flexibility is calculated using the following equation:

$$
C=\delta / P
$$

The mode II fracture energy $\left(G_{\mathrm{IIC}}\right)$ can be calculated using the Irwin-Kies equation:

$$
G_{I I C}=\frac{P^{2}}{2 b} \frac{d C}{d a}
$$

The following mode II fracture energy (in $\mathrm{N} / \mathrm{m}$ ) for the adhesive joint configuration of Figure 1 can be derived as follows:

$$
G_{\mathrm{IIC}}=\frac{P^{2}}{2 b}\left[\frac{a^{2}}{2 E_{1} I_{1}}-\frac{(L-a)^{2}}{8\left(E_{1} I_{1}+E_{2} I_{2}+E_{3} I_{3}\right)}+\frac{9}{30 b}\left[\frac{1}{h_{1} G_{1}}+\frac{1}{h_{2} G_{2}}\right]-\frac{9}{15 b}\left[\frac{1}{h_{1} G_{1}}+\frac{1}{h_{2} G_{2}}+\frac{1}{t G_{3}}\right]\right]
$$

This expression will be used to obtain the mode II fracture energy in the tests described below.

\section{Experimental section}

\subsection{Adherent properties}

The composite samples are made of carbon fibre fabric and epoxy matrix. They were prepared using the hand-moulding technique. The carbon fibre is a reinforced, high-performance 
fabric (HexForce ${ }^{\circledR} 46301 / 1000 / 50 \% 6 \mathrm{~K} \mathrm{HR}$ ) and the matrix is an epoxy resin (Resoltech ${ }^{\circledR}$ 1050/1056). The composite used in the tests consists of five layers of fabric and was cured at room temperature. The other adhesive is an aluminium alloy (series 6160) that is widely used in the automobile industry for its light weight and high resistance to torsion. Table 2 shows the characteristics of the joint and materials employed.

\subsection{Adhesives and surface treatments considered}

Previous studies [36] of the viability of structural adhesives for joining aluminium with composite have concluded that the most suitable adhesives for this type of bond are epoxies (for static mechanical loads that require rigid adhesives) and polyurethane (for dynamic mechanical loads that require flexible adhesives). Table 3 illustrates the results of the study for adhesives and surface treatments that have high rupture stress as well as a high 'value' (ratio of relative technical utility and relative cost).

In this study, the adhesives used were a very high-strength epoxy (Loctite ${ }^{(B)} 9466-$ Henkel) and a two-component polyurethane (Teromix ${ }^{\circledR} 6700-$ Henkel). Table 4 depicts the main characteristics of each of these adhesives. For the ENF flexure tests, the surface treatments of Table 3 were considered. The peel ply treatment consisted of adding a final $80 \mathrm{~g} / \mathrm{m}^{2}, 0.1-\mathrm{mm}$ thick nylon layer to the composite. Once the composite material was cured, the nylon layer was removed, leaving a rough but uniform surface. Sanding was completed manually with sandpaper $(320 \mu \mathrm{m})$ and yielded uniform machined substrates. Sand blasting is a deep-abrasion substrate treatment and was conducted using Guyson sand blasting equipment, model Euroblast 2SF. Artificial corundum with a $120 \mu \mathrm{m}$ grain was used as an abrasive and one pass was made at a distance of $10 \mathrm{~cm}$.

\subsection{The preparation of the adhesive bond arrangements}

Figure 1 illustrates the arrangement and parameters that are characteristic of the adhesive bond used in the ENF tests. The values of these parameters on the tested bonds were as follows: $b=0.01 \mathrm{~m}, t=0.0005 \mathrm{~m}, 2 \mathrm{~L}=0.1 \mathrm{~m}, a=0.025 \mathrm{~m}, h_{1}=0.002 \mathrm{~m}$ and $h_{2}=0.0023 \mathrm{~m}$. To produce the adhesive bond arrangements, a polyethylene tool was manufactured. This tool ensures the reproducibility of the experiments by maintaining the geometric parameters of the adhesive bond (the correct adhesive thickness and substrate alignment). Teflon was placed on a $25 \mathrm{~mm}$ extension corresponding to the pre-crack dimension to generate the notch on the end of the adhesive bond setup. To have the same adhesive thickness on all joints, $0.5 \mathrm{~mm}$ buffers were positioned on the ends of the aluminium adherent. A $125 \mathrm{~g}$ weight was placed on the upper substrate to homogenise the adhesive layer across the joint. Subsequently, the bond

Table 2. The characteristics of the joint and materials employed.

\begin{tabular}{|c|c|c|c|c|c|}
\hline & $\begin{array}{l}\text { Young's } \\
\text { modulus } \\
\left(\mathrm{N} / \mathrm{m}^{2}\right)\end{array}$ & $\begin{array}{c}\text { Second moment of } \\
\text { area } \\
\left(\mathrm{m}^{4}\right)\end{array}$ & $\begin{array}{l}\text { Shear } \\
\text { modulus } \\
\left(\mathrm{N} / \mathrm{m}^{2}\right)\end{array}$ & $\begin{array}{l}\text { Poisson's } \\
\text { ratio }\end{array}$ & $\begin{array}{l}\text { Thickness } \\
\text { (m) }\end{array}$ \\
\hline Aluminium (s 6160) & $6.6 \times 10^{10}$ & $6.66 \times 10^{-12}$ & $2.61 \times 10^{10}$ & 0.26 & 0.0020 \\
\hline $\begin{array}{l}\text { Composite } \\
\quad \text { (Hexforce 46301) }\end{array}$ & $4.35 \times 10^{10}$ & $1.01 \times 10^{-11}$ & $1.69 \times 10^{10}$ & 0.28 & 0.0023 \\
\hline Epoxy Loctite 9466 & $2.6 \times 10^{9}$ & $1.04 \times 10^{-13}$ & $9.29 \times 10^{8}$ & 0.4 & 0.0005 \\
\hline $\begin{array}{l}\text { Polyurethane Teromix } \\
6700\end{array}$ & $6 \times 10^{8}$ & $1.04 \times 10^{-13}$ & $2.08 \times 10^{8}$ & 0.45 & 0.0005 \\
\hline
\end{tabular}


Table 3. The results of the technical-economic analysis for single lap joints.

\begin{tabular}{|c|c|c|c|c|c|c|c|c|}
\hline \multicolumn{3}{|c|}{ Surface treatment } & \multirow[b]{2}{*}{$\begin{array}{c}\text { Failure } \\
\text { stress } \\
\text { (MPa) } \\
\end{array}$} & \multirow[b]{2}{*}{$\begin{array}{l}\text { Range } \\
(\mathrm{MPa})\end{array}$} & \multirow[b]{2}{*}{$\begin{array}{c}\text { Typical } \\
\text { deviation } \\
\text { (MPa) }\end{array}$} & \multicolumn{3}{|c|}{$\begin{array}{c}\text { Technical-economical } \\
\text { evaluation }\end{array}$} \\
\hline $\mathrm{N}^{\circ}$ & $\begin{array}{l}\text { Compound } \\
\text { material } \\
(\mathrm{Ra} \text { in } \mu \mathrm{m})\end{array}$ & $\begin{array}{l}\text { Aluminium } \\
(\mathrm{Ra} \text { in } \mu \mathrm{m})\end{array}$ & & & & $\begin{array}{c}\text { Relative } \\
\text { utility (\%) }\end{array}$ & $\begin{array}{l}\text { Relative } \\
\text { cost }(\%)\end{array}$ & Value \\
\hline \multicolumn{9}{|c|}{ Polyurethane } \\
\hline $\mathrm{P} 1$ & Sanded (1.5) & Sanded (1) & 11.4 & 2.8 & 1.3 & 2.6 & 1.6 & 1.6 \\
\hline P2 & Sanded (1.5) & Sandblasted (1.3) & 14.8 & 3.9 & 2.1 & 10.5 & 4.7 & 2.2 \\
\hline \multicolumn{9}{|c|}{ Epoxy } \\
\hline $\mathrm{E} 2$ & Sanded (1.5) & Sandblasted (1.3) & 18.8 & 6.4 & 3.7 & 18.0 & 6.3 & 2.9 \\
\hline E4 & Peel ply (1.5) & Sandblasted (1.3) & 17.0 & 6.5 & 3.2 & 18.4 & 17.5 & 1.1 \\
\hline
\end{tabular}

Table 4. The properties of the adhesives used.

\begin{tabular}{lcccc}
\hline & \multicolumn{4}{c}{ Properties } \\
\cline { 2 - 5 } Adhesives & $\begin{array}{c}\text { Brookfield viscosity - RVT, } \\
25^{\circ} \mathrm{C}, \mathrm{mPa} \cdot \mathrm{s}(\mathrm{cP})\end{array}$ & $\begin{array}{c}\text { Shear strength ISO } \\
527(\mathrm{MPa})\end{array}$ & $\begin{array}{c}\text { Rest time } \\
(\mathrm{h})\end{array}$ & $\begin{array}{c}\text { Curing } \\
\text { time (h) }\end{array}$ \\
\hline $\begin{array}{l}\text { Epoxy Loctite }{ }^{\circledR} \\
\text { Polyurethane }\end{array}$ & $15,000-50,000$ & 32 & 3 & 72 \\
Teromix $^{(\mathbb{Q}} 6700$ & - & 13 & 0.5 & 48 \\
\hline
\end{tabular}

setups were introduced into a chamber (with controlled temperature and humidity) during the curing time of the adhesive.

\subsection{Conducting the experiment}

After this curing time had elapsed, the bonded materials were removed from the chamber and a dimensional check with a digital calliper was conducted.

For the ENF test, a computer-operated, motorised TN-MD (HOYTOM) was used. Its capacity was $200 \mathrm{kN}$, its stroke was $125 \mathrm{~mm}$ and its displacement speed was set at $2 \mathrm{~mm} / \mathrm{min}$.

A MotionMeter high-speed video camera (Redlake MASD) recorded the ENF tests and, with image correlation, measured the shear slippage of the crack tip. Twenty tests were performed for each of the selected adhesive bonds. To minimise any problem related to the

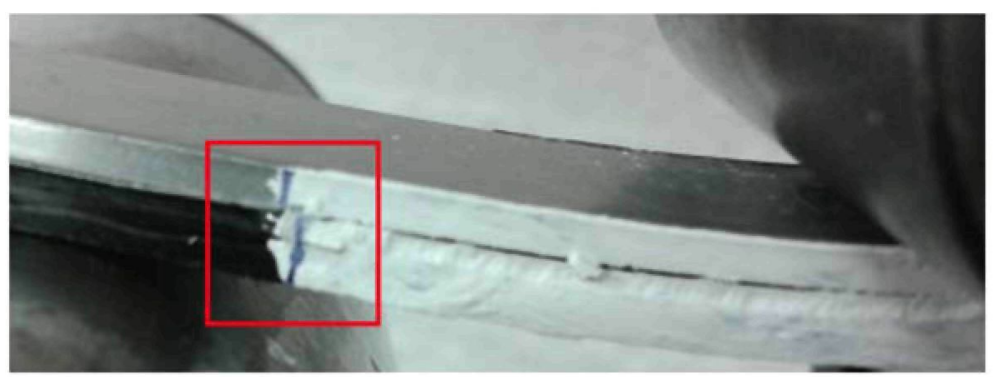

Figure 2. The propagation of the crack. 
actual size of the crack during its propagation, and also the possible influence of the fracture process zone (FPZ), we have chosen the crack length at arrest as the most appropriate parameter. The energy dissipation that is taking place in the FPZ is reflected in the value of the length at crack arrest: the more the energy dissipated at the FPZ, the shorter the length at crack arrest. Figure 2 demonstrates the manner in which the crack propagates during the test.

\section{Results and discussion}

Force-displacement curves obtained for the four selected bonds (P1, P2, E2 and E4) indicate that the bonds with epoxy adhesive provide increased shear strength compared with the bonds with polyurethane adhesive.

Figure 3 shows force-displacement curves for one of the tests performed. In the curve of the adhesive-treated polyurethane P2 (Figure 3(a)), the first peak (point A) is observed which corresponds to the rupture of the adhesive. Once the adhesive rupture is produced, both

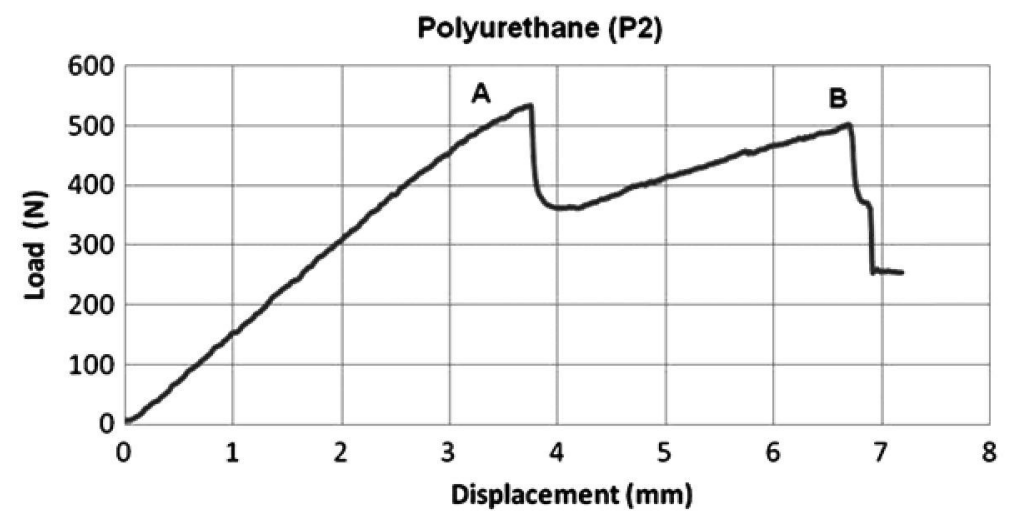

Adhesive polyurethane with treatment P2

(a)

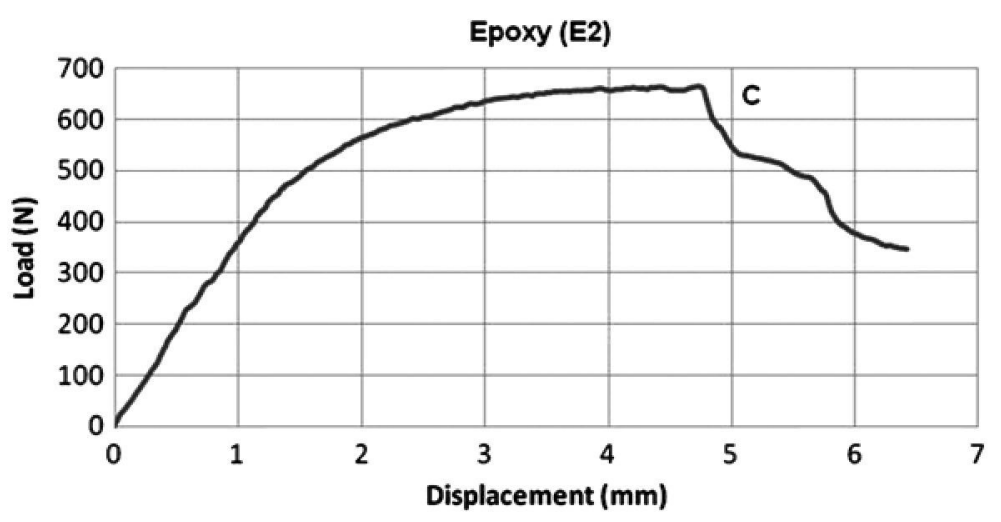

Adhesive epoxy with treatment E2

(b)

Figure 3. The force-displacement curves obtained in the ENF test: (a) adhesive polyurethane with treatment P2 and (b) adhesive epoxy with treatment E2. 
adherents continue to work independently until the rupture of the composite (point B) occurs. From this moment, aluminium is the only resistant component of the joint and undergoes plastic deformation (without rupture). In fact, the remount of load is induced by the approaching of the crack tip to the central loading point which induces compressive stress that hinders a self-similar crack growth, thus inducing a spurious increase of fracture energy.

The curves with E2 treatments (Figure 3(b)) illustrate that the epoxy adhesive confers great rigidity to the bond and causes all of the components of the joint to work in unison until the rupture point; however, at this point, all aspects of the overall joint failed (point $\mathrm{C}$ of Figure 3(b)). In these curves, the adhesive rupture point is not observed directly, as this rupture is hidden by the plastic deformation of the aluminium. However, it is possible to approximately determine the rupture strength of the adhesive through graphical estimation. This approximation is determined by drawing one tangent to the force-displacement curve in the elastic behaviour zone and another tangent in the plastic behaviour zone. The point of intersection of the two tangents represents the peak or the epoxy adhesive rupture strength (point A in Figure 4).

Table 5 provides the results obtained in the flexure test for each of the selected adhesives and treatments. Shear stress of composite material has been obtained using Equation (3), and the average shear stress of the adhesive has been determined using the following equation:

$$
\varphi=\frac{F}{b \times d}
$$

\section{Epoxy (E2)}

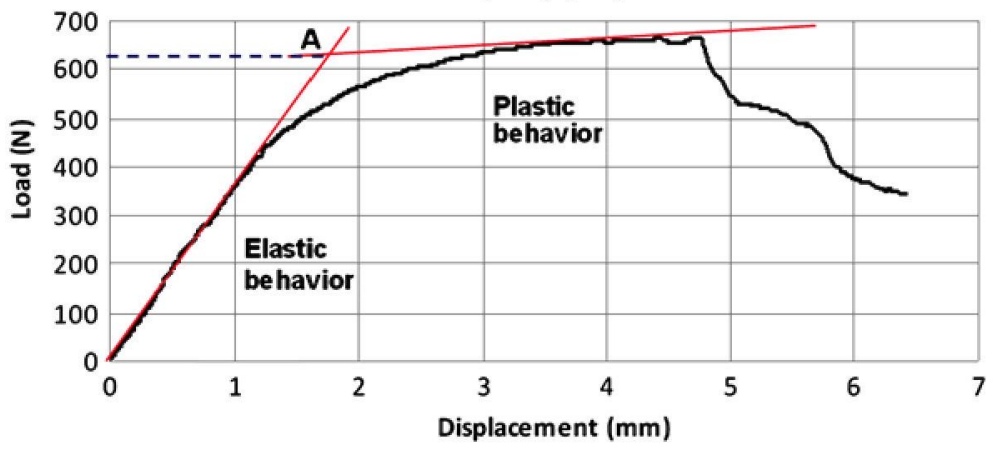

Figure 4. The graphical representation of the epoxy adhesive rupture strength.

Table 5. The ENF test results.

\begin{tabular}{|c|c|c|c|c|c|c|c|c|c|}
\hline & & \multicolumn{4}{|c|}{ Failure of adhesive (MPa) } & \multicolumn{4}{|c|}{ Failure of composite material (MPa) } \\
\hline & & $\varphi \max$ & $\min$ & $\varphi$ mean & $\begin{array}{l}\text { Standard } \\
\text { deviation }\end{array}$ & $\tau \max$ & $\tau \min$ & $\tau$ mean & Standard deviation \\
\hline \multirow[t]{2}{*}{ Polyurethane } & $\mathrm{P} 1$ & 0.44 & 0.27 & 0.34 & 0.04 & 0.44 & 0.41 & 0.52 & 0.06 \\
\hline & P2 & 0.86 & 0.57 & 0.71 & 0.07 & 1.20 & 0.80 & 1.02 & 0.11 \\
\hline \multirow{2}{*}{ Epoxy } & E2 & 1.61 & 0.55 & 1.11 & 0.30 & 2.12 & 0.81 & 1.38 & 0.40 \\
\hline & E4 & 1.58 & 1.11 & 1.39 & 0.12 & 2.37 & 1.66 & 2.10 & 0.20 \\
\hline
\end{tabular}


where $F$ is failure load and $b \times d$ is bonded area $\left(b \times d=0.01 \times 0.075=7.5 \times 10^{-4} \mathrm{~m}^{2}\right)$.

The analysis of Table 5 yielded the following conclusions:

(1) The epoxy adhesive, which was used in conjunction with the sand-blasting treatment for the aluminium and the peel ply treatment for the composite (treatment E4), produces the highest average rupture stress $(1.39 \mathrm{MPa})$ with a standard deviation of $0.12 \mathrm{MPa}$.

(2) The polyurethane adhesive, which was used in conjunction with the sanding treatment for both the aluminium and the composite, not only has the lowest standard deviation $(0.04 \mathrm{MPa})$ but also the lowest average rupture stress $(0.34 \mathrm{MPa})$.

Table 6 shows the rupture strengths obtained in the tests and the corresponding value of the mode II fracture energies, as obtained by applying Equation (11) (which is applicable to the situations involving adherents of different thicknesses and an adhesive of non-negligible thickness).

The analysis of Table 6 yields the following conclusions:

(1) The fracture energy is greater if epoxy adhesive is used rather than polyurethane adhesive, irrespective of the surface treatment used.

(2) For the epoxy adhesive, the E2 surface treatment generates the highest fracture energy value $(1.69 \mathrm{kN} / \mathrm{m}$ compared with $1.10 \mathrm{kN} / \mathrm{m}$ for the $\mathrm{E} 4$ treatment $)$ but has a higher standard deviation than $\mathrm{E} 4$ treatment $(0.60 \mathrm{kN} / \mathrm{m}$ compared with $0.17 \mathrm{kN} / \mathrm{m})$.

(3) For the polyurethane adhesive, the P2 surface treatment results in the highest fracture energy value $(0.69 \mathrm{kN} / \mathrm{m}$ compared with $0.30 \mathrm{kN} / \mathrm{m}$ of the $P 1$ treatment) but results in a standard deviation slightly larger than that of the $\mathrm{P} 1$ treatment $(0.15 \mathrm{kN} / \mathrm{m}$ compared with $0.08 \mathrm{kN} / \mathrm{m}$ of the P1 treatment).

Table 6. Mode II fracture energies.

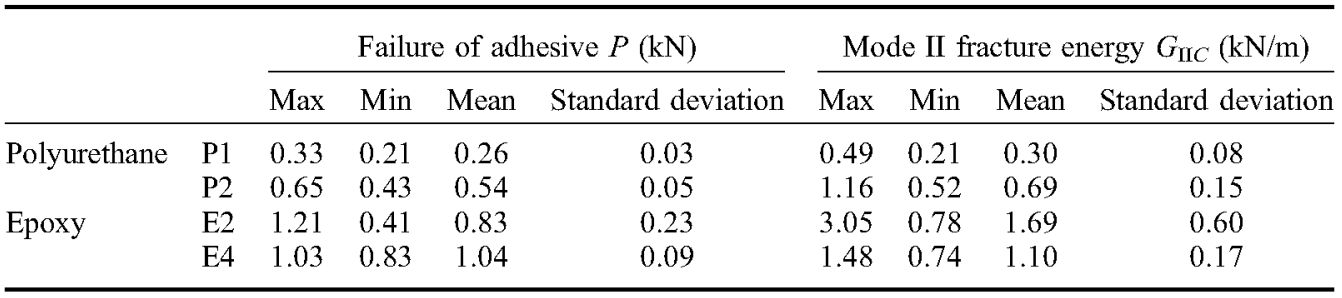

Table 7. The fracture energy from Equation (2) and (11).

\begin{tabular}{|c|c|c|c|c|c|c|c|}
\hline & & \multirow[b]{2}{*}{$\begin{array}{l}\text { Rupture of the } \\
\text { adhesive } P(\mathrm{kN})\end{array}$} & \multirow[b]{2}{*}{$\begin{array}{c}\text { Dis. crack } \\
\delta_{0}(\mathrm{~mm})\end{array}$} & \multicolumn{2}{|c|}{$\begin{array}{c}\text { Mode II fracture } \\
\text { energy } G_{\Pi C}(\mathrm{kN} / \mathrm{m})\end{array}$} & \multicolumn{2}{|c|}{$\begin{array}{c}\text { The difference } \\
\text { between the answers } \\
\text { of Equations (2) and } \\
\text { (11) }\end{array}$} \\
\hline & & & & $\begin{array}{l}\text { Equation } \\
(2)\end{array}$ & $\begin{array}{l}\text { Equation } \\
(11)\end{array}$ & $\begin{array}{c}\text { Absolute } \\
(\mathrm{kN} / \mathrm{m})\end{array}$ & $\begin{array}{c}\text { Relative } \\
(\%)\end{array}$ \\
\hline \multirow[t]{2}{*}{ Polyurethane } & $P 1$ & 0.33 & 6 & 0.29 & 0.30 & 0.01 & 3.4 \\
\hline & $P 2$ & 0.65 & 7 & 0.67 & 0.69 & 0.02 & 3.0 \\
\hline \multirow[t]{2}{*}{ Epoxy } & $E 2$ & 1.21 & 3 & 1.59 & 1.69 & 0.10 & 6.3 \\
\hline & $E 4$ & 1.03 & 4 & 0.99 & 1.10 & 0.11 & 11.1 \\
\hline
\end{tabular}


Thus, it can be concluded that the most suitable adhesive for joining aluminium with composite is epoxy, particularly if applied after a surface sanding treatment for the composite and sand blasting for the aluminium, as these conditions confer great rigidity to the bond, resulting in high values of tensile resistance $(18.8 \mathrm{MPa})$, very good fracture behaviour $(1.69 \mathrm{kN} / \mathrm{m})$, and an excellent technical utility/cost ratio (value $=2.9)$. If more flexible joints are required, a polyurethane adhesive, applied after a sanding treatment for the composite and sand blasting for the aluminium, can be considered an alternative, as it provides good tensile strength $(14.8 \mathrm{MPa})$, reasonable fracture resistance $(0.69 \mathrm{kN} / \mathrm{m})$ and a good technical utility/ cost ratio (value $=2.2$ ). Experiments and results will be described in detail in another paper using the data reduction scheme proposed.

Table 7 illustrates the rupture strength of the adhesive $\left(2 Q_{T}\right)$ and the shear displacement of the crack point $\left(\delta_{0}\right)$ generated by the tests, as well as the corresponding value of the mode II fracture energy obtained from the application of the Ouyang and Li equation (Equation (2)). Furthermore, comparisons (both absolute and relative) are made between the value of mode II fracture energy calculated using Equation (2) and the value obtained by applying Equation (11), which accounts for the non-negligible thickness of the adhesive.

The analysis in Table 7 leads to the following conclusions:

(1) The fracture energy values obtained by applying Equation (11) are greater than those obtained using Equation (2) and demonstrate a relative difference that is greater than $3 \%$ in all cases.

(2) This relative difference is larger in the case of epoxy adhesive than in the case of the polyurethane adhesive, regardless of the surface treatment being considered. The maximum relative difference of approximately $11.1 \%$ between the results of Equation (2) and the results of Equation (11) is obtained with the epoxy adhesive and E4 treatment (peel ply for the composite and sand blasting for the aluminium).

Thus, it can be concluded that the calculation of the mode II fracture energy for adhesives with non-negligible thickness compared with the adherent thicknesses should be based on models that incorporate the influence of the adhesive thickness. This work has shown that Equation (11), which is applicable to joints with a significant adhesive thickness, generates a greater fracture energy value than the value obtained using simplified models. These simplified models consider the adhesive thickness to be zero, as it can be observed from an examination of Equation (2). For the adhesives used in this work (epoxy and polyurethane), the difference between the two calculated approaches exceeds $3 \%$ in all cases, and it reaches a value of $11.1 \%$ for the epoxy in the E4 treatment scheme (peel ply for the composite and sand blasting for the aluminium).

\section{Conclusions}

Structural adhesive bonds are used in critical industrial applications (in the automotive industry, aeronautics, defence and other sectors) in which the safety and health of persons or goods is at risk and a guarantee of adequate reliability is needed; therefore, it is necessary to supplement standard shear tests with an experimental evaluation of the shear resistance of an adhesive bond that incorporates the characteristic criteria of fracture mechanics. This combined study improves the knowledge available about the adhesive bond and the accuracy of the predictions regarding bond performance.

In this study, the ENF test was performed to calculate the fracture energy value at the initiation of the mode II interlaminar crack in an illustrative adhesive bond structure. To 
calculate the fracture energy in the ENF test, two procedures are traditionally used, i.e. EC and CBT. However, these methods do not allow for the calculation of the fracture energy in structural adhesive bonds that contain adherents with different thicknesses and an adhesive with a thickness that is not negligible compared with these adherent thicknesses.

Therefore, in this paper, a specific methodology for calculating the mode II fracture energy was proposed. This methodology incorporates a modification of the Bernoulli-Euler beam theory to calculate the mode $I I$ fracture energy for adhesive bonds containing adherents of different thicknesses and non-negligible adhesive thicknesses.

To illustrate the suitability of the proposed method, the calculation of the fracture energy from the ENF test in aluminium-composite material bonds was performed with two types of adhesive (epoxy and polyurethane) and different surface treatments. From these calculations, the proposed model, which is applicable to bonds with a non-negligible adhesive thickness, predicts a fracture energy value greater than that obtained using the simplified models that consider the thickness of the adhesive to be null. For the adhesives used in this work (epoxy and polyurethane), the difference between these fracture energy values exceeds $3 \%$ in all cases and reaches a value about $11.1 \%$ for the epoxy with the $\mathrm{E} 4$ treatment (which involves peel ply for the composite and sand blasting for the aluminium).

Furthermore, the integration of the results obtained in the ENF tests and the previous data about resistance, utility and single lap joint cost have demonstrated that the most suitable adhesive for joining aluminium with a composite material is epoxy, applied after a surface treatment of sanding for the composite and sand blasting for the aluminium. This adhesive and surface treatment combination provides great rigidity to the bond, resulting in high tensile strength values, very good fracture behaviour and excellent technical utility/cost ratio. If more flexible bonds are required, the use of a polyurethane adhesive after the sanding of the composite and the sand blasting of the aluminium can be considered, as this type of adhesive bond provides good tensile strength, reasonable resistance to fracture and a good technical utility/cost ratio.

In summary, the results obtained in this study have concluded that the calculation of mode II fracture energy for an adhesive that is of a non-negligible thickness compared with its adherents should be based on models that incorporate the influence of this thickness. In this way, the performance of an adhesive bond can be better understood, and the usage of structural adhesive bonds can be promoted.

\section{Acknowledgements}

The authors wish to thank Antonio Conesa of Henkel Loctite for providing the adhesives and dispensers needed to perform the tests, as well as the Technical University of Madrid for funding this project (Q105605177).

\section{References}

[1] Charla KK. Composite materials science and technology. New York (NY): Springer; 2001.

[2] Rastogi N. Design of composite drive shafts for automotive applications. Paper presented at: SAE 2004 World Congress \& Exhibition. Technical paper series, 2004-01-0485; 2004 Mar 8; Detroit, USA.

[3] Cho DH, Lee DG. Manufacture of one-piece automotive drive shafts with aluminum and composite materials. Compos. Struct. 1997;38:309-319.

[4] Grant DR, Adams RD, da Silva LFM. Experimental and numerical analysis of single-lap joints for the automotive industry. Int. J. Adhes. Adhes. 2009;29:405-415.

[5] Adams RD, Comyn J, Wake WC. Structural adhesive joints in engineering. London: Chapman \& Hall; 1997. 
[6] Jin-Hwe K, Jae-Woo J, Tae-Hwan K, Jin-Ho C, Dong-Hyun K. Failure of carbon compositeto-aluminum joints with combined mechanical fastening and adhesive bonding. Compos. Struct. 2006;75:192-198.

[7] Fernlund G, Spelt JK. Mixed-mode fracture characterization of adhesive joints. Compos. Sci. Technol. 1994;50:441-449.

[8] Blackman BRK, Kinloch AJ, Paraschi M. The determination of the mode II adhesive fracture resistance, GIIC, of structural adhesive joints: an effective crack length approach. Eng. Fract. Mech. 2005;72:877-897.

[9] Kim Won-Seock, Lee Jung-Ju. Fracture characterization of interfacial cracks with frictional contact of the crack surfaces to predict failures in adhesive-bonded joints. Eng. Fract. Mech. 2009;76:1785-1799.

[10] Fernández MV, de Moura MFSF, da Silva LFM, Marques AT. Characterization of composite bonded joints under pure mode II fatigue loading. Compos. Struct. 2013;95:222-226.

[11] Osnes H, McGeorge D. Experimental and analytical strength analysis of double-lap joints for marine application. Compos. Part B Eng. 2009;40:29-40.

[12] Boyd SW, Blake JIR, Shenoi RA, Mawella J. Optimisation of steel-composite connections for structural marine applications. Compos. Part B Eng. 2008;39:891-906.

[13] Jumel J, Budzik MK, Ben Salem N, Shanahan MER. Instrumented end notched flexure - crack propagation and process zone monitoring. Part I: modelling and analysis. Int. J. Solids Struct. 2013;50:297-309.

[14] Budzik MK, Jumel J, Ben Salem N, Shanahan MER. Instrumented end notched flexure - crack propagation and process zone monitoring part II: data reduction and experimental. Int. J. Solids Struct. 2013;50:310-319.

[15] Suárez JC, López F. Uniones adhesivas estructurales [Structural adhesive joints]. Madrid: CYTED; 2000.

[16] Reis P, Grundmüller S. Worldwide design handbook. Munich: Loctite European Group; 1998.

[17] LeBack C, Brechet Y, Shercliff HR, Jeggy T, Salvo L. Selection of joining methods in mechanical design. Mater. Des. 2002;23:405-416.

[18] Da Silva LFM, Das Neves PJC, Adams RD, Spelt JK. Analytical models of adhesively bonded joints - part I: literature survey. Int. J. Adhes. Adhes. 2009;29:319-330.

[19] Da Silva LFM, Das Neves PJC, Adams RD, Spelt JK. Analytical models of adhesively bonded joints - part II: comparative study. Int. J. Adhes. Adhes. 2009;29:331-341.

[20] Van Straalen IJJ, Wardenier J, Vogelesang LB, Soetens F. Structural adhesive joints in engineeringdrafting design rules. Int. J. Adhes. Adhes. 1998;18:41-49.

[21] Suarez JC, Diez de Ulzurrún I, Biezma MV, Ruiz Román JM, Martinez MA, Del Real JC, López F. Case studies in adhesives selection. J. Mater. Process. Technol. 2003;143-144:219-224.

[22] Arenas JM, Guillamón A. Proposal for the graphic representation of structural adhesive joints in engineering drawings and their integration in a computer-assisted designing system. Int. J. Adhes. Adhes. 2007;27:122-128.

[23] Arenas JM, Narbón JJ, Alía C. Influence of the surface finish on the shear strength of structural adhesive joints and application criteria in manufacturing processes. J. Adhes. 2009;85:324-340.

[24] Harris JA, Adams RA. Strength prediction of bonded single lap joints by non-linear finite element methods. Int. J. Adhes. Adhes. 1984;4:65-78.

[25] Crocombe AD. Global yielding as a failure criterion for bonded joints. Int. J. Adhes. Adhes. 1989;9:145-153.

[26] Belingardi G, Goglio L, Tarditi A. Investigating the effect of spew and chamfer size on the stresses in metal/plastics adhesive joints. Int. J. Adhes. Adhes. 2002;22:273-282.

[27] Andreassi L, Baudille R, Biancolini ME. Spew formation in a single lap joint. Int. J. Adhes. Adhes. 2007;27:458-468.

[28] Carlsson LA, Gillespie JW, Pipes RB. On the analysis and design of end notch flexure (ENF) for mode II testing. J. Compos. Mater. 1986;20:594-604.

[29] Chen CC, Linzell DG. Modeling end notched flexure tests to establish cohesive element mode II fracture parameters. Eng. Fract. Mech. 2010;77:1338-1347.

[30] Arrese A, Carbajal N, Vargas G, Mujika F. A new method for determining mode II R-curve by the End-Notched Flexure test. Eng. Fract. Mech. 2010;77:51-70.

[31] Todo M, Jarb PYB, Takahashia K. Initiation of a mode-II interlaminar crack from an insert film in the end-notched flexure composite specimen. Compos. Sci. Technol. 2000;60:263-272. 
[32] De Moura MFSF, Campilho RDSG, Gonçalves JPM. Pure mode II fracture characterization of composite bonded joints. Int. J. Solids Struct. 2009;46:1589-1595.

[33] Ouyang Z, Li G. Nonlinear interface shear fracture of end notched flexure specimens. Int. J. Solids Struct. 2009;46:2659-2668.

[34] Branco CAGM. Mecânica dos Materiais [Mechanics of the materials]. Lisboa: Fundaçao Calouste Gulbenkian; 1985.

[35] Da Silva LFM, de Magalhaes AG, de Moura MFSF. Juntas Adesivas Estruturais [Structural adhesive joints]. Porto: Ediçoes Técnicas; 2007.

[36] Arenas JM, Alía C, Narbón JJ, Ocaña R, Recio M. Economical assembly of aluminium parts with composite materials in automotive competitive industry. Adv. Mater. Res. 2012;498:67-72. 